\title{
Endoscopy-assisted subfascial anterior transposition of the ulnar nerve for the treatment of cubital tunnel syndrome \\ Dol:
}

10.1016/j.bjps.2016.09.004

\section{Document Version}

Accepted author manuscript

Link to publication record in Manchester Research Explorer

Citation for published version (APA):

Wong, J. K. F., Hsu, C. C., Lin, C. H., Lien, S. H., \& Lin, Y. T. (2016). Endoscopy-assisted subfascial anterior transposition of the ulnar nerve for the treatment of cubital tunnel syndrome. Journal of plastic, reconstructive \& aesthetic surgery : JPRAS, 69(12), 1704-1710. https://doi.org/10.1016/j.bjps.2016.09.004

\section{Published in:}

Journal of plastic, reconstructive \& aesthetic surgery : JPRAS

\section{Citing this paper}

Please note that where the full-text provided on Manchester Research Explorer is the Author Accepted Manuscript or Proof version this may differ from the final Published version. If citing, it is advised that you check and use the publisher's definitive version.

\section{General rights}

Copyright and moral rights for the publications made accessible in the Research Explorer are retained by the authors and/or other copyright owners and it is a condition of accessing publications that users recognise and abide by the legal requirements associated with these rights.

\section{Takedown policy}

If you believe that this document breaches copyright please refer to the University of Manchester's Takedown Procedures [http://man.ac.uk/04Y6Bo] or contact uml.scholarlycommunications@manchester.ac.uk providing relevant details, so we can investigate your claim.

\section{OPEN ACCESS}




\title{
Endoscopy-assisted subfascial anterior transposition of the ulnar nerve for the treatment of cubital tunnel syndrome
}

\author{
J.K.F. Wong ${ }^{a, b}$, C.C. Hsu ${ }^{a}$, C.H. Lin ${ }^{a}$, S.H. Lien ${ }^{a}$, Y.T. Lin ${ }^{a, c, *}$
}

a Department of Plastic and Reconstructive Surgery, Chang Gung Memorial Hospital, Chang Gung

University, College of Medicine, Taipei, Taiwan

b Plastic Surgery Research, Institute of Inflammation and Repair, University of Manchester, Manchester, UK

c Plastic and Reconstructive Surgery, Department of Surgery, Chang Gung Memorial Hospital, Keelung, Taiwan

Received 4 June 2016; accepted 5 September 2016

\section{KEYWORDS \\ Cubital tunnel; Ulnar nerve; Transposition; Subfascial flap; Endoscopy}

\begin{abstract}
Summary Background: Many techniques have been described to relieve the compression and reduce subluxation of the ulnar nerve following surgery. The subfascial anterior transposition of the ulnar nerve (SfATUN) is one described technique, but involves a long scar, risk of injury to the medial antebrachial cutaneous nerve, and possible nerve ischemia from anterior transposition. We assessed a more refined approach of endoscopy-assisted SfATUN for the treatment of cubital tunnel syndrome.

Methods: A consecutive case series of 21 patients (15 males and 6 females) with evidence of nerve subluxation after ulnar nerve decompression were operated using an endoscopyassisted SfATUN. Each patient was assessed with pre- and postoperative nerve conduction studies, McGowan grading, and recovery of grip strength.

Results: The average age of patients was 54 years (range 23-74 years), and they were followed up for a mean of 9 months (range 3-22 months). Preoperative McGowan grades were eight grade II and 13 grade III. Eighteen of the 21 patients showed improvement, including improvement by two McGowen grades in 8 patients and improvement by one grade in 10 patients. Three grade III patients did not show improvement in grading after surgery. A proportion of $90 \%$ of patients showed significant improvements in motor nerve conduction velocity of the ulnar nerve across the elbow $(p<0.001)$, and all showed some improvement in grip strength $(p<0.001)$. One patient underwent redo neurolysis.
\end{abstract}

\footnotetext{
This work has been presented at 1) IFSSH, Seoul, Korea, $31^{\text {st }}$ Oct $-4^{\text {th }}$ Nov 2010, and 2) the Annual Meeting of Taiwan Society for Surgery of the Hand, Taipei, Taiwan, $19^{\text {th }}$ May 2012.

* Corresponding author. Department of Plastic and Reconstructive Surgery, Department of Surgery, Chang Gung Memorial Hospital, 222, Mai-chin Road, Keelung City 204, Taiwan. Fax: +886 224332655.

E-mail address: linutcgmh@gmail.com (Y.T. Lin).
} 
Conclusion: A combination of endoscopy-assisted SfATUN allows for decompression transposition and reduced strain on the ulnar nerve through a small scar. This is now our standard approach for cubital tunnel syndrome and the "unstable" nerve.

(c) 2016 British Association of Plastic, Reconstructive and Aesthetic Surgeons. Published by Elsevier Ltd. All rights reserved.

\section{Introduction}

Cubital tunnel syndrome (CUTS) is the second most common neuropathy of the upper extremity. The mechanical compression and strain to the ulnar nerve during motion of the elbow are attributed to a number of compression sites including Struthers' ligament, the medial intermuscular septum, the cubital tunnel retinaculum, and Osborne's fascia. ${ }^{1}$ A number of different surgical techniques have been used to relieve the strain and compression, including simple decompression of the cubital tunnel, medial epicondylectomy, and anterior transposition of the ulnar nerve. ${ }^{2}$ More recently, the vogue has been used to perform the surgery by minimal access endoscopic approaches. ${ }^{3}$ There is no single procedure that has been shown to address all the ailments of ulnar neuropathy related to CuTS, and most surgeons use a number of techniques to treat patients. ${ }^{4}$ The essential goal of surgery for CuTS is to correct the etiologic factors contributing to nerve compression on the ulnar nerve at the cubital tunnel, which include removing the compressive pathology, correcting subluxation, and decreasing the strain on the ulnar nerve.

To prevent subluxation and reduce strain on the nerve after decompression of the "unstable" ulnar nerve, different methods of anterior transposition have been advocated. Concerns have been raised in studies showing that the ulnar nerve becomes ischemic on transposition. ${ }^{5}$ However, it has been shown that the nerve can tolerate short segments of devascularization without loss of function. ${ }^{6}$ Different approaches to anterior transposition have been advocated to reroute, decompress, and reduce the strain on the ulnar nerve. Transposing the ulnar nerve can be achieved using either a subcutaneous, subfascial, or submuscular pocket. The subfascial anterior transposition of the ulnar nerve (SfATUN) was proposed by Chuang and Treciak, ${ }^{1}$ which combines detaching and sliding the flexorpronator muscle from the epicondyle to create a new trough for the nerve to pass, and using a fascial sling to maintain the nerve from subluxation. This technique was shown to be an effective method for surgical management of patients with severe CuTs; however, it requires a wide surgical exposure.

In 2006, Hoffmann and Siemionow described an endoscopic, in situ, and atraumatic ulnar nerve decompression using a specialized speculum and illumination equipment. ${ }^{8}$ This technique allowed for minimal invasive decompression of the ulnar nerve and could achieve $93 \%$ good to excellent results in patients with severe CuTS according to a modified Bishop's score. ${ }^{6}$ However, this approach could not address subluxation or strain on the nerve. The objective of this series was to identify whether anterior transposition of the ulnar nerve could be performed safely with endoscopy assistance and provide symptomatic relief in patients with an unstable nerve. The objective of this case series was to check whether SfATUN could be performed through an endoscopic approach and provide adequate symptomatic relief with a low complication rate. In this study, we present our series of CUTS patients treated by endoscopyassisted SfATUN.

\section{Materials and methods}

Our technique was applied to a consecutive series of 21 patients with primary CuTS, including 15 males and six females, between September 2009 and August 2013, conducted by the Trauma division in Plastic and Reconstructive Surgery at Chang Gung Memorial Hospital, Taiwan. Eligible patients for the study included diagnosis of CuTS based on a history of symptoms and clinical signs of sensory loss, weakness, and atrophy along the ulnar nerve distribution; Tinel's sign; or positive elbow flexion sign. The specific inclusion resulted if subluxation of the nerve was visible or palpable on flexion of the elbow, at the time of surgery, following the initial decompression of the ulnar nerve. Patients were excluded from the study if no neck and shoulder symptoms were diagnosed and if neurophysiological findings were normal. All surgery was standardized and performed by the senior author to minimize performance bias. Data collected prospectively included age, pre- and postoperative McGowan grade 9 (Table 1), and nerve conduction latencies across the elbow. All patients were assessed and followed up until a plateau of symptoms by the departmental hand therapy team who graded recovery independent from the surgeon. Grip strength was noted using a Jamar dynamometer before surgery and on the last recorded follow-up. Wilcoxon test was conducted on ordinal data for preoperative and postoperative McGowan scores and paired t-test was performed on nerve conduction latencies across the elbow and grip strength for comparing pre-operative and

Table 1 McGowan grading for ulnar nerve compression.

Grade I Mild lesions with paresthesia in the ulnar nerve distribution and a feeling of clumsiness in the affected hand; no wasting or weakness of the intrinsic muscles

Grade II Intermediate lesions with weak interosseous muscles and muscle wasting

Grade III Severe lesions with paralysis of the interosseous muscles and a marked weakness of the hand 
postoperative values using SPSS version 22 (IBM, Armonk, N.Y.).

\section{Instruments}

Surgery was performed using instruments from the existing components of endoscopic brow lifting and neurological endoscopic sets (Karl Storz, Tuttlingen, Germany) (Figure 1).

\section{Surgical technique}

All patients were operated under general anesthesia in a supine position with the involved elbow flexed to $100-120^{\circ}$ and the shoulder externally rotated. Under tourniquet, a zigzag incision is made obliquely on the medial epicondyle (Figure 2a). The fascia posterior to the intermuscular septum at the upper arm is dissected, and the ulnar nerve proximal to the cubital tunnel retinaculum can be identified between the septum and triceps muscle. The nerve is followed distally and the overlying retinaculum at the cubital tunnel is divided (Video 1). Evidence of ulnar nerve compression is carefully released, and neurolysis is performed under direct loupe magnification. A suprafascial dissection of $8-10 \mathrm{~cm}$ is performed proximal and distal to the medial epicondyle along the direction of the ulnar nerve. A Papavero-Caspar Speculum retractor is inserted into the subcutaneous pocket, and the blades are opened to create a space. A 4.0-mm endoscope (Hopkins $^{\circledR}$ II Forward-Oblique Telescope $30^{\circ}$ ) with the Optic Dissector is introduced. Proximally, the fascia posterior to the intermuscular septum overlying the ulnar nerve is unroofed. The ulnar nerve is dissected and mobilized with an endoscopic freer and KLICKline Fine Scissors (Video 2). Distally, Osborne's fascia is released, and the ulnar nerve was dissected between the two heads of flexor carpi ulnaris (FCU) muscle until the first branch of motor nerve to the FCU (Video 3). The vessel along the ulnar nerve is included when possible and mobilized with the nerve.

Supplementary video related to this article can be found at http://dx.doi.org/10.1016/j.bjps.2016.09.004.

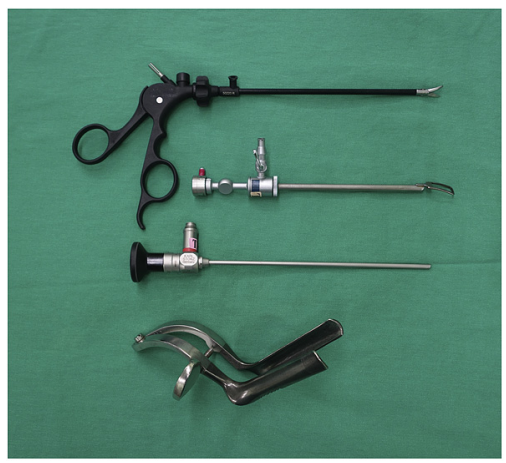

Figure 1 Instruments used for endoscopic neurolysis: KLICKline Fine Scissors, Optic Dissector, 4.0-mm $30^{\circ}$ endoscope, and Papavero-Caspar MR Speculum (from top to bottom).
A smaller subcutaneous pocket is dissected anterolaterally to the medial epicondyle for elevating a semicircular fascial flap of the flexor-pronator muscle (Video 4). A trough measuring $2 \mathrm{~cm}$ in width is created by detaching the origin of the flexor-pronator muscle group and sliding it distally (Video 5). The ulnar nerve is transposed anteriorly into the trough, and its new position is secured by reattachment of the fascial flap to the intermuscular septum of the flexor-pronator muscles (Video 6). The course of the transposed nerve is checked to ensure that there is no iatrogenic compression and kinking of the ulnar nerve. Passive mobilization of the elbow is made to confirm that there is no subluxation of the ulnar nerve after anterior transposition. An open corrugated drain, cut $6 \mathrm{~mm}$ wide, and a bulky dressing are used to reduce the risk of hematoma formation caused by dissection of the FCU muscle.

Supplementary video related to this article can be found at http://dx.doi.org/10.1016/j.bjps.2016.09.004.

\section{Postoperative management and rehabilitation}

The elbows are free to mobilize gradually within pain limits and splints are not used. Patients are allowed to initiate gentle active upper extremity range of motion at the second or third postoperative day. ${ }^{10}$ Scar massage was initiated after the wound had healed to aid desensitization of the scar and promote collagen remodeling. Similarly, nerve-gliding exercises were started to prevent fibrotic adhesions from reforming around the released nerves. ${ }^{11}$ Neuromuscular electrical stimulation and motor retraining exercises were started in those patients with hypothenar muscle wasting and claw deformity in ring and little fingers. Pre- and postoperative nerve conduction and grip strength studies were conducted on all patients.

\section{Results}

A total of 21 patients met the inclusion criteria for the study. The average age of the patients was 56 (24-74) years, and they were stratified into McGowan grades: where there was, 8 patients were in grade II and 13 patients in grade III preoperatively. Patients were followed up for an average of $8(3.0-22.1)$ months. A significant improvement in symptoms was seen in 19 of 21 patients $(p<0.001)$. Eight patients showed an improvement by two McGowan grades, and 10 patients showed an improvement by one grade (Table 2). Three patients who were McGowan grade III preoperatively did not show any improvement. One patient (case 13) showed no response of the ulnar nerve in the nerve conduction study before the surgery, was followed up for 11 months, and had repeat neurolysis. One patient (case 21,65 years of age) experienced elbow dislocation followed by intrinsic muscle wasting 2 years before the surgery. The numbness improved postoperatively, but the motor function did not recover. Tendon transfers were performed secondarily. The third patient (case 19) also showed no response of the ulnar nerve in the nerve conduction study and extensive wasting of the intrinsic musculature, which failed to improve following surgery. The majority (90\%) of the patients showed improvements in the motor nerve 

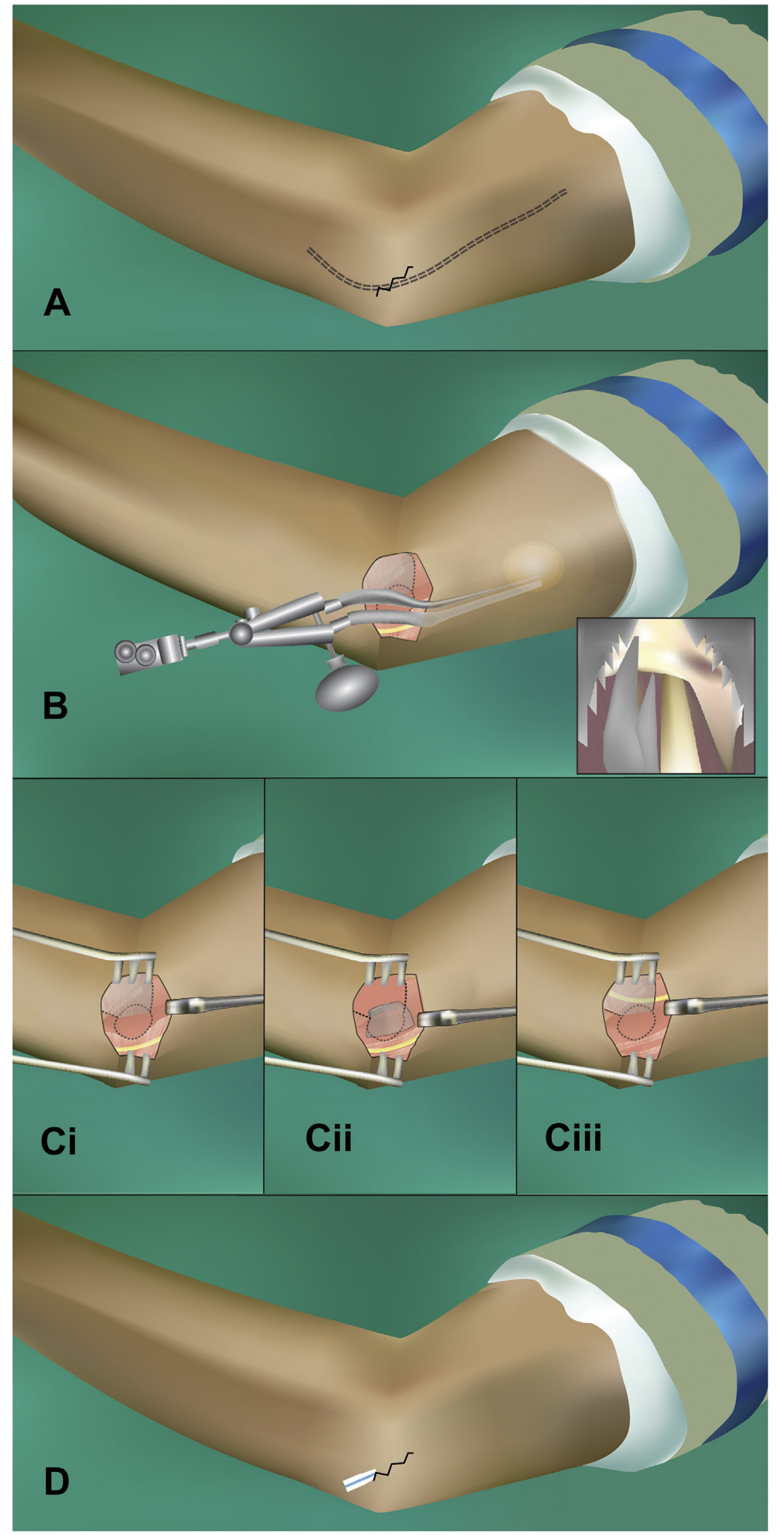

Please cite this article in press as: Wong JKF, et al., Endoscopy-assisted subfascial anterior transposition of the ulnar nerve for the treatment of cubital tunnel syndrome, Journal of Plastic, Reconstructive \& Aesthetic Surgery (2016), http://dx.doi.org/10.1016/ j.bjps.2016.09.004 
Table 2 Operative findings and McGowen grades pre- and postoperatively.

\begin{tabular}{|c|c|c|c|c|c|c|c|c|c|c|c|c|}
\hline \multirow[t]{2}{*}{ Case } & \multirow[t]{2}{*}{ Gender } & \multirow[t]{2}{*}{ Age } & \multicolumn{3}{|c|}{ Compression site } & \multirow[t]{2}{*}{$\begin{array}{l}\text { Follow-up } \\
\text { (months) }\end{array}$} & \multicolumn{2}{|c|}{$\begin{array}{l}\text { McGowan } \\
\text { grades }\end{array}$} & \multicolumn{2}{|c|}{$\begin{array}{l}\text { Nerve conduction } \\
\text { latency }(\mathrm{m} / \mathrm{s})\end{array}$} & \multicolumn{2}{|c|}{$\begin{array}{l}\text { Grip strength } \\
\text { (kg force) }\end{array}$} \\
\hline & & & $\begin{array}{l}\text { Osborne's } \\
\text { fascia }\end{array}$ & $\begin{array}{l}\text { Cubital tunnel } \\
\text { retinaculum }\end{array}$ & $\begin{array}{l}\text { Arcade of } \\
\text { Struther's }\end{array}$ & & Pre-op & Post-op & Pre-op & Post-op & Pre-op & Post-op \\
\hline 1 & $M$ & 69 & - & + & - & 6.4 & III & II & 15 & 8 & 28 & 40 \\
\hline 2 & $M$ & 63 & - & + & - & 22.1 & II & 0 & 9 & 10.5 & 42 & 48 \\
\hline 3 & $M$ & 53 & + & + & - & 4.9 & III & 1 & 9 & 6 & 30 & 38 \\
\hline 4 & $M$ & 60 & - & - & - & 11.1 & III & 1 & 17.6 & 14.1 & 34 & 36 \\
\hline 5 & $\mathrm{~F}$ & 55 & + & + & - & 6.0 & II & 1 & 8.1 & 7.5 & 32 & 37 \\
\hline 6 & $M$ & 58 & - & + & - & 16.8 & III & II & 13.9 & 10.9 & 32 & 36 \\
\hline 7 & $M$ & 48 & - & + & - & 9.0 & III & II & 13.8 & 9.2 & 24 & 34 \\
\hline 8 & $M$ & 23 & + & + & - & 3.0 & II & 0 & 14.5 & 9.8 & 30 & 37 \\
\hline 9 & $\mathrm{~F}$ & 66 & + & + & - & 5.9 & II & 1 & 13.2 & 11.5 & 25 & 35 \\
\hline 10 & $M$ & 25 & + & - & - & 9.6 & II & I & $>20$ & 17.2 & 12 & 34 \\
\hline 11 & $M$ & 64 & + & + & - & 5.1 & II & I & 8.7 & 7.7 & 28 & 36 \\
\hline 12 & $\mathrm{~F}$ & 64 & + & + & - & 9.9 & III & I & 10.9 & 7.2 & 25 & 32 \\
\hline 13 & $M$ & 60 & + & + & - & 11.5 & III & III & $>20$ & $>20$ & 30 & 38 \\
\hline 14 & $M$ & 59 & + & - & - & 8.9 & III & 1 & 13.9 & 10.2 & 16 & 30 \\
\hline 15 & $M$ & 74 & + & - & - & 9.0 & III & I & 12.4 & 11.5 & 20 & 24 \\
\hline 16 & $\mathrm{~F}$ & 34 & + & - & - & 8.5 & III & II & 8.9 & 7.2 & 12 & 23 \\
\hline 17 & $\mathrm{~F}$ & 54 & + & - & - & 6.7 & II & I & 8.4 & 7.7 & 16 & 22 \\
\hline 18 & $M$ & 61 & + & + & - & 3.5 & III & I & 9.4 & 8.9 & 16 & 24 \\
\hline 19 & $M$ & 52 & + & - & - & 3.0 & III & III & $>20$ & 15.4 & 35 & 46 \\
\hline 20 & $\mathrm{~F}$ & 57 & + & + & - & 3.1 & II & 1 & $>20$ & 16.5 & 21 & 26 \\
\hline 21 & $M$ & 65 & + & - & - & 3.8 & III & III & $>20$ & $>20$ & 10 & 14 \\
\hline
\end{tabular}

conduction velocity of the ulnar nerve across the elbow $(p<0.001)$; this included the patients who showed no improvement in McGowan grades. A significant number of patients had objective improvement in grip strength postoperatively $(p<0.001)$. No complications were noted, and there was no report of injury of the medial antebrachial cutaneous nerve.

\section{Discussion}

There is a trend to minimize the incision for cubital tunnel surgery to allow for quicker recovery and a less troublesome scar. ${ }^{12}$ However, in the context of the reducing strain on the nerve or the nerve subluxing after this procedure, anterior transposition is recommended. ${ }^{13}$ The ability to perform both an extensive decompression and transposition of the nerve through a small incision is the natural evolution of this procedure when faced with an unstable nerve. Our unit has extensive experience in subfascial transposition of the ulnar nerve (SFATUN) $)^{14}$ originally described by Chuang et al., and hence, it seemed ideal to develop this technique into a less invasive procedure. In the present study, we showed that an endoscopy-assisted SFATUN can be performed to achieve satisfactory symptomatic relief and improvement in nerve conduction velocities in a cohort of patients with nerve instability following decompression. The procedure is safe and can be performed with little risk of damaging the antebrachial cutaneous nerve. Two other groups have described similar endoscopic techniques, one using a transparent sheath to guide the endoscope ${ }^{15}$ and the other using $\mathrm{CO}_{2}$ insufflation to produce a subcutaneous pocket to allow fascial release. ${ }^{16}$ The limitation of this study was that a number of surgical options are available, whereas the number of unstable nerves at presentation is low, and hence a comparison between the methods was not possible. As this was a feasibility study, we did not compare the outcomes and complication rates between simple decompression and the eSFATUN, and indeed future studies will be required to address this. There have been several studies comparing the results of different surgical interventions for CUTS, but the ideal solution has not been defined yet. Mowlavi et al. stratified patients into mild, moderate, and severe stages and compared the results of nonoperative management, simple decompression, medial epicondylectomy, anterior subcutaneous transposition, and anterior submuscular transposition. They found that (1) for patients with mild symptoms, all modalities produced similar degrees of satisfaction; (2) for patients with moderate symptoms, submuscular transposition was most

Figure 2 Schematic of endoscopy-assisted subfascial anterior transposition of the ulnar nerve. A. Zigzag incision over the cubital tunnel and nerve outline marked. B. Insertion of speculum after decompression of the ulnar nerve and subcutaneous dissection. Inset shows downward view of the endoscope decompressing the fascia over the nerve. C. Fascial flap is raised, reflected from the flexor origin above the medial epicondyle, and the nerve is transposed into the muscle trough. D. Wound is closed and corrugated drain is left in situ for $24 \mathrm{~h}$. 
efficacious; and (3) for patients with severe symptoms, current therapeutic modalities were not consistently effective. ${ }^{17}$ We do not prefer to use the subcutaneous transposition or an anterior skin flap, as this causes the nerve to become quite superficial in thin patients, whereas our technique recreates a well-vascularized wide fascial tunnel to stop the nerve from displacement. A metaanalysis of randomized controlled trials comparing the simple decompression with anterior transposition found that there was no difference in motor nerve-conduction velocities or clinical outcome scores between simple decompression and ulnar nerve transposition for the treatment of CuTS. ${ }^{18}$ It could be stressed that the majority of studies did not comprise large enough study groups that enabled to determine differences between the different treatment modalities. ${ }^{19}$ Macadam et al. reviewed 10 studies including 449 simple decompressions, 342 subcutaneous transpositions, and 115 submuscular transpositions and did not show any statistically significant differences between the groups, however a trend could be seen favouring transposition of the nerve that may be relevent with more rigorous study methodology. ${ }^{19}$

Novak and Mackinnon reviewed the trend for cubital tunnel compression in the US and found that most surgeons used more than one operative procedure in their treatment of patients with CuTS. The selection of the surgical procedure was influenced by evidence of muscle atrophy (84\%), abnormal nerve conduction studies (51\%), and failed nonoperative treatment (49\%). ${ }^{4}$ Focusing on correction of the precise etiological factors appears to be the key to obtain satisfactory results, and this requires a systematic decompression of a long segment of the ulnar nerve with appropriate translocation and reconfiguration of the anatomy as opposed to a specific operation. Our observations are that this can best be obtained by direct visualization and decompression of the nerve with relocation of the nerve out of its vulnerable position around the elbow and in a safe subfascial pocket.

Previously described techniques like the SfATUN can result in injury to the medial antebrachial cutaneous nerves (MACN) because of its wide dissection. In a series of 97 patients, two cutaneous nerves were identified near the elbow, with one $1.8 \mathrm{~cm}$ proximal to the medial epicondyle and the other on an average of $3.1 \mathrm{~cm}$ distal to the medial epicondyle, which have been reported to be prone to injury. ${ }^{20}$ Our use of a smaller zigzag incision enables branches of the MACN to be carefully viewed and avoided. Once the speculum retractor was inserted, the branches of the MACN would be protected in the subcutaneous layer. We did not injure any MACN in our series.

Another concern about SfATUN was devascularization and its consequence of ischemia insult to the nerve. Studies have shown that anterior transposition can result in the reduction in blood flow to the nerve in the immediate postoperative period, which persisted until the third postoperative day. Recovery of perfusion is gradually reestablished by the seventh day. ${ }^{5}$ Interestingly, in vivo models of ulnar nerve transposition do not show that dissection of the mesoneurium results in a significant change in ulnar nerve response latency or conduction velocity. In our series, all the electrophysiological studies showed improvement in motor nerve conduction velocity of the ulnar nerve across the elbow for all the patients, including the patients who showed no improvement in McGowan grades. It is therefore evident that in clinical cases, the transposition of nerve does not appear to be of detriment to nerve recovery, provided the compression element has been resolved.

We feel that when the transposition of the ulnar nerve is desired, our technique of endoscopic assistance with the SfATUN provides an adequate release of the ulnar nerve through a reduced exposure and ultimately reduces strain and instability of the subluxing nerve. The procedure has a relatively short learning curve if previously experienced in conventional anterior transposition of the ulnar nerve, and allows the nerve to be safely and securely transposed in a subfascial trough. There were no complications with our procedure, and our patients were satisfied with the results; we therefore plan to compare this procedure with simple decompression alone in future studies.

\section{Financial disclosure statement}

None of the authors have a financial interest in any of the products, devices, or drugs mentioned in this manuscript.

The authors confirm that this article relates to surgical technique and as such it does not fall under the due restriction of the Declaration of Helsinki and does not require Clinical Trial Registration.

\section{Funding}

This study was part funded by the British Society of Surgery of the Hand (BSSH), British Association of Plastic Reconstructive and Aesthetic Surgeons (BAPRAS) and Royal College of Surgeons of Edinburgh Ethicon travel bursaries.

\section{Author contribution}

J KF Wong is the author and illustrator of this manuscript.

Yu-Tee Lin is the principal and corresponding author who developed the technique, provided cases, and performed surgeries. SH Lien provided all the postoperative rehabilitation procedures.

$\mathrm{CC}$ Hsu and $\mathrm{CH}$ Lin provided input to the manuscript as senior surgeons within the division.

\section{Conflict of interest statement}

None.

\section{Acknowledgment}

The authors would like to acknowledge Professor David Chuang for his teaching of the subfascial anterior transposition that allowed for the subsequent development of this procedure. 


\section{References}

1. Chuang D. Subfascial anterior transposition: a modified method for treatment of cubital tunnel syndrome. Tech Hand Up Extrem 1998;2:178-83.

2. Caliandro P, La Torre G, Padua R, Giannini F, Padua L. Treatment for ulnar neuropathy at the elbow. Cochrane Database Syst Rev 2012; 7:CD006839.

3. Hoffmann R, Lubahn J. Endoscopic cubital tunnel release using the Hoffmann technique. J Hand Surg Am 2013;38:1234-9.

4. Novak C, Mackinnon SE. Selection of operative procedures for cubital tunnel syndrome. Hand 2009;4:50-4.

5. Ogata K, Manske PR, Lesker PA. The effect of surgical dissection on regional blood flow to the ulnar nerve in the cubital tunnel. Clin Orthop Relat Res 1985:195-8.

6. Ogata K, Shimon S, Owen J, Manske PR. Effects of compression and devascularisation on ulnar nerve function. A quantitative study of regional blood flow and nerve conduction in monkeys. $J$ Hand Surg Br 1991;16:104-8.

7. Teoh LC, Yong FC, Tan SH, Andrew Chin YH. Anterior subfascial transposition of the ulnar nerve. J Hand Surg Br 2003; 28:73-6.

8. Hoffmann R, Siemionow M. The endoscopic management of cubital tunnel syndrome. J Hand Surg B 2006;31B:23-9.

9. McGowan AJ. The results of transposition of the ulnar nerve for traumatic ulnar neuritis. J Bone Jt Surg Br 1950;32:293-301.

10. Lund AT, Amadio PC. Treatment of cubital tunnel syndrome: perspectives for the therapist. J Hand Ther 2006;19:170-8.

11. Walsh MT. Interventions in the disturbances in the motor and sensory environment. J Hand Ther 2012;25:202-18. quiz 19.
12. Watts AC, Bain GI. Patient-rated outcome of ulnar nerve decompression: a comparison of endoscopic and open in situ decompression. J Hand Surg Am 2009;34:1492-8.

13. Nabhan A, Ahlhelm F, Kelm J, et al. Simple decompression or subcutaneous anterior transposition of the ulnar nerve for cubital tunnel syndrome. J Hand Surg Br 2005;30:521-4.

14. Chuang DC, Treciak MA. Subfascial anterior transposition: a modified method for the treatment of cubital tunnel syndrome (CuTS). Tech Hand Up Extrem Surg 1998;2:178-83.

15. Konishiike T, Nishida K, Ozawa M, Ozaki T. Anterior transposition of the ulnar nerve with endoscopic assistance. J Hand Surg Eur Vol 2011;36:126-9.

16. Jiang S, Xu W, Shen Y, Xu JG, Gu YD. Endoscopy-assisted cubital tunnel release under carbon dioxide insufflation and anterior transposition. Ann Plast Surg 2012;68:62-6.

17. Mowlavi A, Andrews K, Lille S, et al. The management of cubital tunnel syndrome: a meta-analysis of clinical studies. Plastic Reconstr Surg 2000;106:327-34.

18. Zlowodzki M, Chan S, Bhandari M, et al. Ant erior transposition compared with simple decompression for treatment of cubital tunnel syndrome. A metaanalysis of randomized, controlled trials. J Bone Jt Surg Am 2007;89:2591-8.

19. Macadam S, Gandhi R, Bezuhly M, Lefaivre KA. Simple decompression versus anterior subcutaneous and submuscular transposition of the ulnar nerve for cubital tunnel syndrome: a meta-analysis. J Hand Surg Am 2008:33A.

20. Lowe JI, Maggi SP, Mackinnon SE. The position of crossing branches of the medial antebrachial cutaneous nerve during cubital tunnel surgery in humans. Plastic Reconstr Surg 2004; 114:692-6. 